\title{
Calcium intake and the 10-year incidence of self-reported vertebral fractures in women and men: The Japan Public Health Centre-based Prospective Study
}

\author{
Kazutoshi Nakamura ${ }^{1}$, Norie Kurahashi ${ }^{2}$, Junko Ishihara ${ }^{2}$, Manami Inoue ${ }^{2}$, Shoichiro Tsugane ${ }^{2}$ and for the \\ Japan Public Health Centre-based Prospective Study Group \\ ${ }^{1}$ Department of Community Preventive Medicine, Niigata University Graduate School of Medical and Dental Sciences, \\ 1-757 Asahimachi-dori, Niigata 951-8510, Japan \\ ${ }^{2}$ Epidemiology and Prevention Division, Research Center for Cancer Prevention and Screening, National Cancer Center, \\ 5-1-1 Tsukiji, Chuo-ku, Tokyo 104-0045, Japan
}

(Received 21 November 2007 - Revised 7 April 2008 - Accepted 15 April 2008 - First published online 13 June 2008 )

The purpose of this study was to evaluate the effect of low Ca intake on the 10-year incidence of vertebral fractures in cohorts I and II of the Japan Public Health Centre-based Prospective Study. The baseline studies were conducted in 1990-1994, with the follow-up studies conducted after 10 years. We analysed 33970 subjects aged 40-59 years in cohort I and 41664 subjects aged 40-69 years in cohort II. At baseline, the intake of $\mathrm{Ca}$ was assessed as a predictor, using validated FFQ. A meta-analysis was performed to estimate a summary relative risk (RR) for the two cohort studies. The 10-year cumulative incidences of self-reported vertebral fractures were $0.38 \%$ for cohort I and $0.56 \%$ for cohort II. In women, lower $\mathrm{Ca}$ intake was associated with a higher incidence of vertebral fractures $(P$ for trend $=0.001)$, with the lowest quartile of Ca intake having a significantly higher incidence $(0 \cdot 89 / 1000$ persons per year or RR $2 \cdot 10$ (95\% CI 1.25, 3.55)) than that $(0 \cdot 42 / 1000$ persons per year) of the highest. In addition, the RR calculated using energy-adjusted Ca intake (by the residual method) as an outcome was 1.92 ( $95 \%$ CI 1.28, 2.88). However, no such association was observed in men. An increase of Ca intake should be considered as a preventive strategy for vertebral fractures in peri- and post-menopausal women with a low $\mathrm{Ca}$ intake.

Calcium: Cohort studies: Japanese: Vertebral fractures

A bone fracture is the most tragic outcome of osteoporosis, an age-related disease characterized by generalized skeletal fragility $^{(1)}$. Some fractures decrease the levels of activities of daily living and the quality of life in the elderly. A vertebral fracture is one such fracture. Patients with vertebral fractures often have impaired mobility and/or suffer from back pain ${ }^{(2)}$. Vertebral fractures have been reported to be more common in $\operatorname{Japan}^{(3)}$ than in the USA ${ }^{(4)}$ and, as such, their prevention deserves a high priority.

$\mathrm{Ca}$ is a nutrient essential for the maintenance of normal bone metabolism and bone mass and its insufficient intake results in loss of bone and the eventual development of osteoporosis. Therefore, sufficient intake of $\mathrm{Ca}$ is considered to be the first step for preventing bone loss, osteoporosis and, presumably, osteoporotic fractures in adults. For example, high Ca intake ( $\geq 1000-1200 \mathrm{mg} / \mathrm{d})$ is recommended as an adequate intake for adults in the USA ${ }^{(5)}$. Ca intake among the Japanese is generally low. The National Nutrition Survey of Japan reported that the average $\mathrm{Ca}$ intake in adults (aged $40-69$ years) is estimated to be $492-602 \mathrm{mg} / \mathrm{d}^{(6)}$, even though $\mathrm{Ca}$ intake of $600-700 \mathrm{mg} / \mathrm{d}$ has been recommended as an adequate intake for this age group ${ }^{(7)}$. In spite of this, there have only been a few studies conducted in Japan that have examined whether low $\mathrm{Ca}$ intake adversely affects bone-related parameters. A previous study reported that low dietary $\mathrm{Ca}$ intake in elderly women was significantly associated with high levels of bone resorption markers ${ }^{(8)}$. In addition, the bottom half of the population has been shown to have lower values on bone ultrasound characterization $^{(9)}$. On the one hand, these reports suggest that low $\mathrm{Ca}$ intake in the Japanese population may affect the incidence of vertebral fractures. However, despite the lower Ca intake in the Japanese, the incidence of hip fractures in Japan has been reported to be lower than that of Europeans and North Americans ${ }^{(10,11)}$. This, on the other hand, may suggest that low $\mathrm{Ca}$ intake in the Japanese may only slightly, if at all, increase the incidence of vertebral fractures. Previously, there have been far fewer epidemiological studies on vertebral than on hip fractures. To our knowledge, no epidemiological studies on vertebral fractures have ever been conducted to test and clarify the effect of low $\mathrm{Ca}$ intake in East Asians, particularly the Japanese, in whom Ca intake is generally low.

The Japan Public Health Centre-based Prospective Study (JPHC Study) is a large, population-based cohort study, designed to reveal risk factors for chronic diseases, including cancers, CVD, diabetes and others. It targets around 117000

Abbreviations: JPHC Study, Japan Public Health Centre-based Prospective Study; RR, relative risk.

* Corresponding author: Dr Kazutoshi Nakamura, fax +81 25227 0764, email kazun@med.niigata-u.ac.jp 
middle-aged and elderly Japanese women and men nationwide ${ }^{(12)}$. In the present study, we analysed the levels of Ca intake and the 10-year incidence of vertebral fractures. The purpose of this study was to test whether low Ca intake is associated with increased incidence of vertebral fractures in Japanese adults.

\section{Subjects and methods}

The JPHC Study consists of two cohorts, cohort I and cohort II, with the subjects selected from nationwide areas of Japan. The following participants met our exclusion criteria according to the baseline survey: (1) subjects who reported a history of vertebral fractures, diabetes mellitus or cancers (of the stomach, lung, colon, liver, breast or the uterus); (2) subjects who were undergoing corticosteroid therapy; (3) subjects who were taking medicine for suspected osteoporosis; (4) subjects who were taking female hormones. In addition, subjects whose reported dietary energy intake fell within the upper or lower $2.5 \%$ were excluded. It is the policy of the JPHC Study to exclude extreme values for dietary intake, because we consider these reports may be unreliable ${ }^{(13)}$. The energy cut-off points were 3255 and $9427 \mathrm{~kJ}$ (778 and $2253 \mathrm{kcal}) / \mathrm{d}$ for cohort I women, 4527 and $14878 \mathrm{~kJ}(1082$ and $3556 \mathrm{kcal}) / \mathrm{d}$ for cohort I men, 2423 and $7159 \mathrm{~kJ}(579$ and $1711 \mathrm{kcal}) / \mathrm{d}$ for cohort II women and 3523 and 12221 $\mathrm{kJ}(842$ and $2921 \mathrm{kcal}) / \mathrm{d}$ for cohort II men. The present study protocol was approved by the institutional review board of the National Cancer Centre, Tokyo, Japan. Detailed information describing the study design, conduct and participant profiles has been published previously ${ }^{(12)}$. The followup surveys were conducted 10 years after the baseline survey.

\section{Subjects of Japan Public Health Centre-based Prospective Study cohort I}

The JPHC Study cohort I consisted of four public health centre-based cohorts in fourteen municipalities within four prefectures (Akita, Iwate, Nagano and Okinawa), which represent distinct geographical areas of $\mathrm{Japan}^{(14)}$, and a health check-up cohort in the Tokyo metropolitan district. The baseline survey for cohort I was conducted in 1990, except in Katsushika, where questionnaires were administered during health check-ups from 1990-1994. Among 61595 residents (31 613 women and 29982 men) between 40-59 years of age with a registered address, $50245(81.6 \%$ response rate $)$ returned the questionnaire. Of the 50245 subjects who completed the baseline survey, 37861 (response rate $75.4 \%$ ) returned the follow-up questionnaire in 2000. After excluding 1998 subjects who met our exclusion criteria and 1819 subjects whose dietary energy intake was within the extreme range, 34044 subjects were included in the final analysis.

\section{Subjects of Japan Public Health Centre-based Prospective Study cohort II}

In 1993-1994, cohort II was added to the JPHC Study. The JPHC Study cohort II consisted of seven population-based cohorts in fourteen municipalities, in six prefectures (Niigata, Ibaraki, Osaka, Kochi, Nagasaki and Okinawa) ${ }^{(14)}$. Among 78825 residents (40085 women and 38740 men) between
40-69 years of age with a registered address, 63216 (response rate $80.2 \%$ ) returned the questionnaire. Of the 63216 subjects who completed the baseline survey, 48615 (response rate $76.9 \%$ ) returned the follow-up questionnaire in 2003-2004. After excluding 4457 subjects who met our exclusion criteria and 2323 subjects whose dietary energy intake was within the extreme range, 41835 subjects were included in the final analysis.

\section{Measurements at baseline}

Demographic, lifestyle and nutritional information was obtained through a self-administered questionnaire. Subjects' age, sex, body height, body weight, past medical history and medications were recorded. BMI was calculated by dividing the weight $(\mathrm{kg})$ by the square of the height $\left(\mathrm{m}^{2}\right)$. Subjects were asked about the frequency at which they engage in sport activities and the answers were coded as 1 for less than once per month, 2 for one to three times per month, 3 for once or twice per week and 4 for three or more times per week. Smoking and alcohol use habits were also recorded. Dietary intake, including $\mathrm{Ca}$, vitamin $\mathrm{D}$ and total energy, was assessed by two validated FFQ, a forty-four item FFQ for cohort $\mathrm{I}^{(15)}$ and a fifty-two item FFQ for cohort $\mathrm{II}^{(16)}$. Each participant was asked how often during the previous month he or she had consumed specific foods and beverages, on average. The amount of each food consumed was calculated by multiplying the frequency of consumption with the portion size. The appropriate portion size for each food was estimated separately for each cohort using a validation study conducted in a sub-sample of each cohort ${ }^{(17)}$. The individuals' daily intake of nutrients, including $\mathrm{Ca}$, protein and vitamin $\mathrm{D}$, was calculated using the Standardized Tables of Food Composition, 5th ed. ${ }^{(18)}$. The validity of the FFQ with regard to assessing intake was evaluated against $7 \mathrm{~d}$ dietary records collected as a reference during each of the four seasons. Regarding $\mathrm{Ca}$ intake, the Spearman's correlation coefficient between the forty-four item FFQ and the reference $7 d$ record was 0.46 for women and 0.56 for men, and that between the fifty-two item FFQ and the reference record was 0.50 for women and 0.53 for men.

\section{Follow-up survey after 10-years}

The subjects were asked to report previously developed fractures within the lumbar region (herein defined as a vertebral fracture) in the 10-year follow-up period. The question was posed in the following manner: 'Has your doctor(s) told you that you have a fracture at the lumbar region? If so, when was the fracture first diagnosed - in the past 10 years or earlier?' The subjects were also asked not to report vertebral fractures due to high-energy trauma, such as traffic and occupational accidents, as a vertebral fracture in this study.

\section{Statistical analysis}

Statistical analysis was performed separately in cohort I and cohort II. The cumulative incidence of vertebral fractures in the 10-year follow-up period was calculated for each quartile of continuous variables (except for age) and for each level of discrete variables. The relative risk (RR) of vertebral fractures 
was calculated for continuous variables (except for age), for each quartile relative to the fourth quartile. RR for $\mathrm{Ca}$ and vitamin $\mathrm{D}$ intakes were also calculated using energy adjustment by the residual method ${ }^{(19)}$. The RR of vertebral fractures was calculated for discrete variables, for each level relative to the reference level. A test for linear trend was performed using logistic regression, with an occurrence of vertebral fracture as the outcome variable and each discrete variable as a predictor. RR adjusted for age, body weight, smoking, alcohol use, frequency of sports activity, area, vitamin D intake and energy were estimated using the OR yielded by multiple logistic regression analysis. The questionnaires used in JPHC Study cohort I and cohort II differed slightly with regard to food items and thus the following statistical methods (meta-analysis) were used to obtain summary $\mathrm{RR}$ in relation to $\mathrm{Ca}$ intake. We calculated separate estimates for cohort I and cohort II and then analysed the combined result using a fixed-effects model. That is:

\section{Results}

Baseline characteristics of the subjects in cohorts I and II, stratified by sex, are shown in Table 1. Overall, men tended to have higher values than women, except for age and $\mathrm{Ca}$ intake in both cohort I and cohort II. Percentage frequency of smoking and drinking habits of the subjects is also shown in Table 1. The 10-year cumulative incidences of vertebral fractures were $0.38 \%$ for cohort I overall, $0.42 \%$ for cohort I women and $0.33 \%$ for cohort I men and $0.56 \%$ for cohort II overall, $0.66 \%$ for cohort II women and $0.44 \%$ for cohort II men. In total, the incidence was $0.55 \%$ for women and $0.39 \%$ for men $(P=0.001)$.

Table 2 shows unadjusted RR of vertebral fractures occurring within 10 years in cohort $\mathrm{I}$, with the values for each level calculated relative to a reference level. Age was the strongest predictor of vertebral fractures among the variables measured in this cohort $(P$ for trend $<0.001)$. The 10 -year incidence of vertebral fractures was significantly higher in the 50-54 year group and the 55-59 year group than in the 40-44 year group for both sexes. Lower (energy-unadjusted) $\mathrm{Ca}$ intake and less frequent milk consumption in women was associated with a higher incidence of vertebral fractures, with the 'less than once per week' group having significantly higher incidence than the 'five or more times per week' group. Lower vitamin D intake in men was associated with lower incidence of vertebral fractures, with the first quartile having significantly lower incidence than the fourth quartile.

Table 3 shows unadjusted RR of vertebral fractures occurring within 10 years in cohort II, with each level being relative to the reference level of the respective predictor variable. Age was the strongest predictor of vertebral fractures among variables measured in this cohort. The 10-year incidence of vertebral fractures was significantly higher in any of the age groups in women $(P$ for trend $<0 \cdot 001)$, as well as in the 60-64 and the 65-69 year groups in men, compared with the 40-44 year group $(P$ for trend $<0.001)$. Lower $\mathrm{Ca}$ intake in women was associated with higher incidence of vertebral fractures, with the first quartile having significantly higher incidence than the fourth quartile.

Table 4 shows adjusted RR of vertebral fractures occurring within 10 years for women and men according to quartiles of $\mathrm{Ca}$ intake in cohorts I and II. Lower Ca intake in women was significantly associated with higher incidence of vertebral

Table 1. Baseline characteristics of the subjects in cohorts I and II, stratified by sex*

(Means and standard deviations or percentage)

\begin{tabular}{|c|c|c|c|c|c|c|c|c|}
\hline & \multicolumn{4}{|c|}{ Cohort I } & \multicolumn{4}{|c|}{ Cohort II } \\
\hline & \multicolumn{2}{|c|}{$\begin{array}{l}\text { Women } \\
(n \text { 18524) }\end{array}$} & \multicolumn{2}{|c|}{ Men (n 15520) } & \multicolumn{2}{|c|}{$\begin{array}{l}\text { Women } \\
(n 22596)\end{array}$} & \multicolumn{2}{|c|}{ Men (n 19239) } \\
\hline & Mean & SD & Mean & SD & Mean & SD & Mean & SD \\
\hline Age (years) & $49 \cdot 3$ & 5.9 & $49 \cdot 2$ & $6 \cdot 0$ & 53.6 & $8 \cdot 7$ & 53.0 & $8 \cdot 6$ \\
\hline Height $(\mathrm{cm})$ & $151 \cdot 8$ & $5 \cdot 3$ & $164 \cdot 0$ & $6 \cdot 1$ & $152 \cdot 0$ & $5 \cdot 8$ & $164 \cdot 2$ & $6 \cdot 5$ \\
\hline $\operatorname{BMI}\left(\mathrm{kg} / \mathrm{m}^{2}\right)$ & 23.5 & $3 \cdot 1$ & 23.5 & $2 \cdot 8$ & $23 \cdot 3$ & 3.4 & 23.5 & 3.0 \\
\hline Total energy† $(\mathrm{kJ} / \mathrm{d})$ & 5962 & 1255 & 9125 & 2284 & 4619 & 954 & 7284 & 1849 \\
\hline Total energy† $(\mathrm{kcal} / \mathrm{d})$ & 1425 & 300 & 2181 & 546 & 1104 & 228 & 1741 & 442 \\
\hline Ca intake† (mg/d) & 512 & 245 & 520 & 276 & 334 & 142 & 332 & 142 \\
\hline Vitamin D intake† $(\mu \mathrm{g} / \mathrm{d})$ & $5 \cdot 8$ & $2 \cdot 8$ & $6 \cdot 3$ & $3 \cdot 2$ & 4.8 & 2.6 & 5.7 & 3.3 \\
\hline Proportion of current smokers (\%) & \multicolumn{2}{|c|}{$5 \cdot 2$} & \multicolumn{2}{|c|}{51.7} & \multicolumn{2}{|c|}{$5 \cdot 6$} & \multicolumn{2}{|c|}{50.2} \\
\hline Proportion of frequent drinkers (five or more times per week) (\%) & \multicolumn{2}{|c|}{3.9} & \multicolumn{2}{|c|}{$50 \cdot 1$} & \multicolumn{2}{|c|}{$3 \cdot 8$} & \multicolumn{2}{|c|}{$47 \cdot 2$} \\
\hline
\end{tabular}

${ }^{*}$ For details of subjects and procedures, see Subjects and methods.

† Nutritional parameters were assessed by two different FFQ for cohort I and cohort II. 
Table 2. Unadjusted relative risk (RR) of vertebral fractures occurring within 10 years in cohort I*

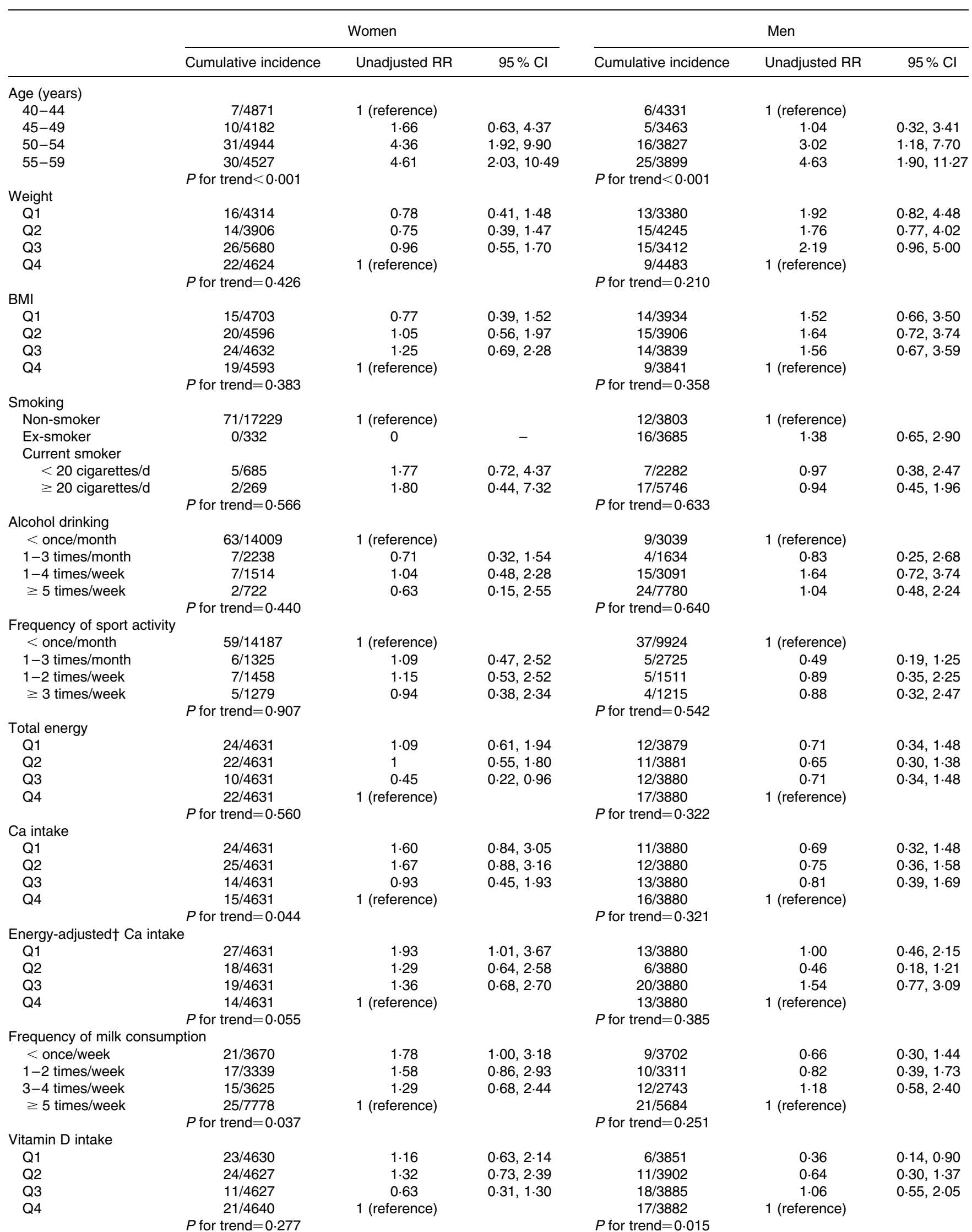


Table 2. Continued

\begin{tabular}{|c|c|c|c|c|c|c|}
\hline & \multicolumn{3}{|c|}{ Women } & \multicolumn{3}{|c|}{ Men } \\
\hline & Cumulative incidence & Unadjusted RR & $95 \% \mathrm{Cl}$ & Cumulative incidence & Unadjusted RR & $95 \% \mathrm{Cl}$ \\
\hline \multicolumn{7}{|c|}{ Energy-adjusted $†$ vitamin D intake } \\
\hline Q1 & $23 / 4631$ & 1.05 & $0.58,1.87$ & $8 / 3880$ & 0.50 & $0.21,1.17$ \\
\hline Q2 & $25 / 4631$ & $1 \cdot 14$ & $0 \cdot 64,2 \cdot 01$ & $8 / 3880$ & 0.50 & $0.21,1 \cdot 17$ \\
\hline Q3 & $8 / 4631$ & 0.36 & $0.16,0.82$ & $20 / 3880$ & 1.25 & $0.65,2 \cdot 41$ \\
\hline \multirow[t]{2}{*}{ Q4 } & $22 / 4631$ & 1 (reference) & & $16 / 3880$ & 1 (reference) & \\
\hline & $P$ for trend $=0.311$ & & & $P$ for trend $=0.027$ & & \\
\hline
\end{tabular}

Q1, first quartile; Q2, second quartile; Q3, third quartile; Q4, fourth quartile.

Cut-off values for quartiles are as follows:

Weight: 49,53 and $59 \mathrm{~kg}$ for women; 57,63 and $68 \mathrm{~kg}$ for men.

BMI: $21.4,23.2$ and $25.3 \mathrm{~kg} / \mathrm{m}^{2}$ for women; $21.6,23.4$ and $25.2 \mathrm{~kg} / \mathrm{m}^{2}$ for men

Energy: 5075, 5874 and $6753 \mathrm{~kJ}(1213,1404$ and $1614 \mathrm{kcal}) / \mathrm{d}$ for women; 7351,8962 and $10774 \mathrm{~kJ}(1757,2142$ and $2575 \mathrm{kcal}) / \mathrm{d}$ for men.

Ca intake: 326,464 and $677 \mathrm{mg} / \mathrm{d}$ for women; 324,452 and $673 \mathrm{mg} / \mathrm{d}$ for men.

Vitamin D intake: $3.7,5.5$ and $7.6 \mu \mathrm{g} / \mathrm{d}$ for women; $3.9,5.9$ and $8.1 \mu \mathrm{g} / \mathrm{d}$ for men.

${ }^{*}$ For details of subjects and procedures, see Subjects and methods.

† Adjusted by the residual method.

fractures in cohorts I and II (except for energy-adjusted Ca intake in cohort I), but there were no significant associations in men.

A meta-analysis was conducted to determine summary RR of $\mathrm{Ca}$ intake for vertebral fractures for cohorts I and II. Table 5 shows the results of the 10-year vertebral fracture $\mathrm{RR}$ analysis of each quartile relative to the fourth quartile for $\mathrm{Ca}$ intake in women and men. Lower $\mathrm{Ca}$ intake in women was associated with higher incidence of vertebral fractures, with the first quartile having significantly higher incidence $(0 \cdot 89 / 1000$ persons per year) than the fourth quartile $(0 \cdot 42 / 1000$ persons per year). The population-attributable fraction of a vertebral fracture in women relative to the fourth quartile (an unexposed group) was 27.0\% (pd 0.81 and RR 1.5 for the first-third quartiles as an exposed group). By contrast, there were no significant associations between $\mathrm{Ca}$ intake and vertebral fractures in men.

A meta-analysis was conducted to determine summary associations between vitamin D intake and vertebral fractures for cohorts I and II, because there was a significant association between them in cohort I men (Table 3). However, no significant associations were found between vitamin $D$ intake and vertebral fractures (adjusted $P$ for trend $=0.267$ ) or between energy adjusted vitamin $D$ intake and vertebral fractures (adjusted $P$ for trend $=0 \cdot 398$ ).

\section{Discussion}

This is the first cohort study exploring the risk of vertebral fractures in Asian women whose Ca intake is low. It demonstrated that women with lower $\mathrm{Ca}$ intake had a higher incidence of vertebral fractures. The National Nutrition Survey ${ }^{(22)}$ reported that mean $\mathrm{Ca}$ intake of the Japanese aged between $40-70$ years was $562 \mathrm{mg} / \mathrm{d}$, on average, which is lower than that of people in many European and North American countries.

The present study used two different FFQ for the two large cohorts, which prevented us from directly analysing the combined data of cohorts I and II. Mean values of total energy measured by the FFQ used in cohort II were lower than those measured by the FFQ used in cohort I, while the mean values of anthropometric variables, such as weight and BMI, were almost the same in cohorts I and II. This, together with the results of the National Nutrition Survey, indicates that the FFQ used in cohort II underestimated the values of nutritional parameters. Because there is little regional difference in $\mathrm{Ca}$ intake in Japan ${ }^{(6,22)}$, and because cohorts I and II were large enough, the actual $\mathrm{Ca}$ intakes of cohorts I and II were considered to be almost equivalent. This warranted our meta-analysis.

The meta-analysis of the current study demonstrated that the subjects in the first quartile of $\mathrm{Ca}$ intake had a twice higher risk of clinical vertebral fractures than those in the fourth quartile, but only in women. The FFQ used in this study may not necessarily give an accurate $\mathrm{Ca}$ intake, even though their rank correlations with the $7 \mathrm{~d}$ dietary record method were acceptable. The National Nutrition Survey of Japan (using a dietary record method) is expected to have provided more accurate data on $\mathrm{Ca}$ intake ${ }^{(6)}$. It showed that 25 th, 50th and 75th percentiles of Ca intake in 50-69 year old women were 362,532 and $716 \mathrm{mg} / \mathrm{d}$, respectively. In general, peri- and early post-menopausal women with a $\mathrm{Ca}$ intake of $350 \mathrm{mg} / \mathrm{d}$ or lower have a significantly higher risk of vertebral fractures than those with a Ca intake of $700 \mathrm{mg} / \mathrm{d}$ or higher, which is an adequate $\mathrm{Ca}$ intake for post-menopausal women based on the 2005 Dietary Reference Intakes for Japanese ${ }^{(7)}$.

The accuracy of self-reported vertebral fractures is a major concern in the current study. A study in the USA reported that agreements between self-reports for single-site fractures and medical records were lower for clinical spine fractures than for fractures of the appendicular bones, such as hip and arm fractures $^{(23)}$. We believe, however, that the accuracy of selfreported fractures among the Japanese are better than previously thought. There have been no published data regarding this issue in Japanese populations. However, an ongoing cohort study (Muramatsu study) on fractures in elderly Japanese (aged 69 years and over) ${ }^{(24)}$ indicates a high positive predictive value of self-reported vertebral fractures. In that study, among eight self-reported vertebral fractures in a 4-year follow-up, seven were radiographically diagnosed as vertebral fractures, as identified by orthopaedists using the diagnostic criteria of the Japanese Society of Bone and Mineral Metabolism (personal data) ${ }^{(25)}$. Although this result was derived from a study with a shorter follow-up period and limited cases, it warrants high accuracy of self-reporting 
Table 3. Unadjusted relative risk (RR) of vertebral fractures occurring within 10 years in cohort II*

\begin{tabular}{|c|c|c|c|c|c|c|}
\hline & \multicolumn{3}{|c|}{ Women } & \multicolumn{3}{|c|}{ Men } \\
\hline & Cumulative incidence & Unadjusted RR & $95 \% \mathrm{Cl}$ & Cumulative incidence & Unadjusted RR & $95 \% \mathrm{Cl}$ \\
\hline \multicolumn{7}{|l|}{ Age (years) } \\
\hline $40-44$ & 4/4626 & 1 (reference) & & $11 / 4301$ & 1 (reference) & \\
\hline $45-49$ & $11 / 3146$ & 4.04 & $1 \cdot 29,12 \cdot 69$ & 7/2925 & 0.94 & $0.36,2 \cdot 41$ \\
\hline $50-54$ & $20 / 4291$ & $5 \cdot 39$ & $1 \cdot 84,15 \cdot 76$ & $11 / 3658$ & $1 \cdot 18$ & $0.51,2.71$ \\
\hline $55-59$ & $22 / 3630$ & $7 \cdot 01$ & $2 \cdot 42,20 \cdot 32$ & $16 / 3045$ & 2.05 & $0.95,4.42$ \\
\hline \multirow[t]{2}{*}{$65-69$} & $49 / 3066$ & $18 \cdot 48$ & $6 \cdot 68,51 \cdot 16$ & $19 / 2251$ & 3.30 & $1.57,6.92$ \\
\hline & $P$ for trend $<0.001$ & & & $P$ for trend $<0.001$ & & \\
\hline \multicolumn{7}{|l|}{ Weight } \\
\hline Q1 & $39 / 5628$ & $1 \cdot 14$ & $0.74,1.78$ & $26 / 4461$ & $1 \cdot 22$ & $0 \cdot 70,2 \cdot 12$ \\
\hline Q2 & $40 / 4813$ & 1.37 & $0.88,2 \cdot 13$ & $12 / 4790$ & 0.52 & $0.26,1.05$ \\
\hline Q3 & $32 / 5712$ & 0.93 & $0.58,1.48$ & $22 / 4961$ & 0.93 & $0.52,1.65$ \\
\hline Q4 & $39 / 6443$ & 1 (reference) & & $24 / 5027$ & 1 (reference) & \\
\hline & $P$ for trend $=0.281$ & & & $P$ for trend $=0.838$ & & \\
\hline \multicolumn{7}{|l|}{ BMI } \\
\hline Q2 & $34 / 5646$ & 0.91 & $0.57,1.45$ & $18 / 4752$ & 0.76 & $0.41,1.40$ \\
\hline Q3 & $41 / 5560$ & 1.11 & $0.72,1.73$ & $19 / 4704$ & 0.81 & $0.44,1.47$ \\
\hline Q4 & $37 / 5590$ & 1 (reference) & & $24 / 4806$ & 1 (reference) & \\
\hline & $P$ for trend $=0.749$ & & & $P$ for trend $=0.754$ & & \\
\hline \multicolumn{7}{|l|}{ Smoking } \\
\hline Non-smoker & $137 / 21044$ & 1 (reference) & & $20 / 4817$ & 1 (reference) & \\
\hline Ex-smoker & $2 / 248$ & 1.24 & $0.31,4.98$ & $18 / 4761$ & 0.91 & $0.48,1.72$ \\
\hline \multicolumn{7}{|l|}{ Current smoker } \\
\hline$<20$ cigarettes/d & 8/839 & 1.46 & $0.72,2.98$ & $16 / 2437$ & 1.58 & $0.82,3.05$ \\
\hline \multirow[t]{2}{*}{$\geq 20$ cigarettes $/ d$} & $2 / 415$ & 0.74 & $0.18,2.98$ & $30 / 7203$ & 1.00 & $0.57,1.76$ \\
\hline & $P$ for trend $=0.462$ & & & $P$ for trend $=0.823$ & & \\
\hline \multicolumn{7}{|l|}{ Alcohol drinking } \\
\hline$<$ once/month & $126 / 17749$ & 1 (reference) & & $20 / 4208$ & 1 (reference) & \\
\hline $1-3$ times/month & $7 / 1906$ & 0.52 & $0.24,1 \cdot 11$ & $2 / 1512$ & 0.28 & $0.07,1.19$ \\
\hline 1-4 times/week & $6 / 1895$ & 0.45 & $0.20,1.01$ & $23 / 4112$ & $1 \cdot 18$ & $0 \cdot 65,2 \cdot 14$ \\
\hline$\geq 5$ times/week & $8 / 843$ & 1.34 & $0.66,2.72$ & $35 / 8792$ & 0.84 & $0.48,1.45$ \\
\hline & $P$ for trend $=0.035$ & & & $P$ for trend $=0.519$ & & \\
\hline Frequency of sport acti & & & & & & \\
\hline 1-2 times/week & 7/2285 & 0.42 & $0.20,0.90$ & $8 / 1835$ & 0.83 & $0.40,1.73$ \\
\hline$\geq 3$ times/week & $16 / 2240$ & 0.99 & $0.59,1.66$ & $8 / 2007$ & 0.76 & $0.37,1.58$ \\
\hline & $P$ for trend $=0.215$ & & & $P$ for trend $=0.202$ & & \\
\hline Total energy & & & & & & \\
\hline Q1 & $34 / 5649$ & 0.97 & $0.61,1.56$ & $23 / 4809$ & 0.92 & $0.52,1.62$ \\
\hline Q2 & $43 / 5649$ & $1 \cdot 23$ & $0.79,1.92$ & $15 / 4810$ & 0.60 & $0.32,1.14$ \\
\hline Q3 & 385648 & 1.09 & $0.69,1.72$ & $21 / 4810$ & 0.84 & $0.47,1.50$ \\
\hline Q4 & $35 / 5650$ & 1 (reference) & & $25 / 4810$ & 1 (reference) & \\
\hline & $P$ for trend $=0.941$ & & & $P$ for trend $=0.558$ & & \\
\hline Ca intake & & & & & & \\
\hline Q1 & $45 / 5649$ & 1.67 & $1.04,2 \cdot 68$ & $21 / 4809$ & 1.50 & $0.76,2.95$ \\
\hline Q2 & $42 / 5649$ & 1.56 & $0.96,2.52$ & $23 / 4810$ & 1.64 & $0.85,3 \cdot 19$ \\
\hline Q3 & $36 / 5649$ & 1.33 & $0.81,2 \cdot 19$ & $26 / 4809$ & 1.86 & $0.97,3.55$ \\
\hline Q4 & $27 / 5649$ & 1 (reference) & & $14 / 4811$ & 1 (reference) & \\
\hline & $P$ for trend $=0.029$ & & & $P$ for trend $=0.379$ & & \\
\hline Energy-adjusted $† \mathrm{Ca}$ in & & & & & & \\
\hline Q1 & $50 / 5649$ & 1.92 & $1 \cdot 20,3.08$ & $23 / 4810$ & 1.57 & $0.80,3.07$ \\
\hline Q2 & $36 / 5649$ & 1.38 & $0.84,2.29$ & $25 / 4810$ & 1.79 & $0.93,3.43$ \\
\hline Q3 & $38 / 5649$ & 1.46 & $0.89,2.40$ & $23 / 4810$ & 1.64 & $0.85,3.19$ \\
\hline Q4 & $26 / 5649$ & 1 (reference) & & $14 / 4809$ & 1 (reference) & \\
\hline & $P$ for trend $=0.011$ & & & $P$ for trend $=0.205$ & & \\
\hline Frequency of milk cons & tion & & & & & \\
\hline Rarely & $31 / 3162$ & 1.67 & $1 \cdot 08,2 \cdot 60$ & $19 / 3315$ & 1.62 & $0.87,3.01$ \\
\hline Occasionally & $29 / 4147$ & 1.19 & $0.76,1.87$ & $27 / 4858$ & 1.57 & $0.89,2.78$ \\
\hline $1-2$ times/week & $10 / 2325$ & 0.73 & $0.37,1.44$ & $6 / 2428$ & 0.70 & $0.28,1.73$ \\
\hline 3-4 times/week & $21 / 3251$ & 1.10 & $0.67,1.82$ & $9 / 2363$ & 1.08 & $0.49,2.35$ \\
\hline$\geq 5$ times/week & $54 / 9222$ & 1 (reference) & & $21 / 5946$ & 1 (reference) & \\
\hline & $P$ for trend $=0.052$ & & & $P$ for trend $=0.060$ & & \\
\hline Vitamin D intake & & & & & & \\
\hline Q1 & $38 / 5615$ & 0.94 & $0.60,1.45$ & $25 / 4807$ & 1.04 & $0.60,1.82$ \\
\hline Q2 & $33 / 5667$ & 0.80 & $0.51,1.27$ & $13 / 4787$ & 0.54 & $0.28,1.07$ \\
\hline Q3 & $38 / 5647$ & 0.93 & $0.60,1.44$ & $22 / 4832$ & 0.91 & $0.51,1.63$ \\
\hline Q4 & $41 / 5667$ & 1 (reference) & & $24 / 4813$ & 1 (reference) & \\
\hline & $P$ for trend $=0.631$ & & & $P$ for trend $=0.780$ & & \\
\hline
\end{tabular}


Table 3. Continued

\begin{tabular}{|c|c|c|c|c|c|}
\hline \multicolumn{3}{|c|}{ Women } & \multicolumn{3}{|c|}{ Men } \\
\hline Cumulative incidence & Unadjusted RR & $95 \% \mathrm{Cl}$ & Cumulative incidence & Unadjusted RR & $95 \% \mathrm{Cl}$ \\
\hline \multicolumn{6}{|l|}{ intake } \\
\hline $41 / 5649$ & 0.98 & $0.64,1.50$ & $24 / 4810$ & 1.09 & $0.61,1.94$ \\
\hline $35 / 5649$ & 0.83 & $0.53,1.30$ & $17 / 4810$ & 0.77 & $0.41,1.45$ \\
\hline $32 / 5649$ & 0.76 & $0.48,1.21$ & $21 / 4810$ & 0.95 & $0.53,1.73$ \\
\hline $42 / 5649$ & 1 (reference) & & $22 / 4809$ & 1 (reference) & \\
\hline$P$ for trend $=1.000$ & & & $P$ for trend $=0.923$ & & \\
\hline
\end{tabular}

Q1, first quartile; Q2, second quartile; Q3, third quartile; Q4, fourth quartile.

Cut-off values for quartiles are as follows:

Weight: 49,53 and $58 \mathrm{~kg}$ for women; 57,63 and $69 \mathrm{~kg}$ for men.

BMI: $21 \cdot 2,23.0$ and $25.1 \mathrm{~kg} / \mathrm{m}^{2}$ for women; $21.5,23.4$ and $25.3 \mathrm{~kg} / \mathrm{m}^{2}$ for men

Energy: 3954, 4581 and $5238 \mathrm{~kJ}(945,1095$ and $1252 \mathrm{kcal}) / \mathrm{d}$ for women; 5895, 7100 and $8556 \mathrm{~kJ}(1409,1697$ and $2045 \mathrm{kcal}) / \mathrm{d}$ for men.

Ca intake: 213, 329 and $445 \mathrm{mg} / \mathrm{d}$ for women; 219, 309 and $436 \mathrm{mg} / \mathrm{d}$ for men.

Vitamin D intake: $2 \cdot 9,4.4$ and $6.3 \mu \mathrm{g} / \mathrm{d}$ for women; 3.3. 5.1 and $7.7 \mu \mathrm{g} / \mathrm{d}$ for men.

${ }^{*}$ For details of subjects and procedures, see Subjects and methods.

† Adjusted by the residual method.

in the present study, which targeted a younger population. In Japan, vertebral fractures are more common than other fractures, such as hip fractures, and are more prevalent in Japan than in Western countries ${ }^{(4,26)}$. Consequently, both patients and orthopaedists in Japan are more likely to be attentive to this type of fracture.

Several cohort studies have examined the association between $\mathrm{Ca}$ intake and incident vertebral fractures, but none has demonstrated a significant relationship. No association between $\mathrm{Ca}$ intake and morphometric vertebral fractures was

Table 4. Adjusted relative risk (RR) of vertebral fractures occurring within 10 years for women and men according to quartiles of calcium intake in cohorts I and $\mathrm{II}^{*}$

\begin{tabular}{|c|c|c|c|c|}
\hline & \multicolumn{2}{|c|}{ Women } & \multicolumn{2}{|l|}{ Men } \\
\hline & Adjusted RR† & $95 \% \mathrm{Cl}$ & Adjusted RR† & $95 \% \mathrm{Cl}$ \\
\hline \multicolumn{5}{|c|}{ Ca intake in cohort I } \\
\hline Q1 & 2.77 & $1 \cdot 13,6 \cdot 78$ & 0.90 & $0.32,2.54$ \\
\hline Q2 & $2 \cdot 30$ & $1 \cdot 10,4 \cdot 84$ & 0.79 & $0.34,1.80$ \\
\hline Q3 & 1.02 & $0.45,2.28$ & 0.96 & $0.44,2.09$ \\
\hline Q4 & $\begin{array}{l}1 \text { (reference) } \\
P \text { for trend }=0.0\end{array}$ & & \multicolumn{2}{|l|}{$P$ for trend $=0.916$} \\
\hline \multicolumn{5}{|c|}{ Energy-adjusted $\ddagger \mathrm{Ca}$ intake in cohort I } \\
\hline Q1 & 2.06 & $1.06,4.02$ & 1.05 & $0.44,2.53$ \\
\hline Q2 & $1 \cdot 20$ & $0.59,2.45$ & 0.53 & $0.20,1.46$ \\
\hline Q3 & 1.47 & $0.73,2.94$ & 1.70 & $0.83,3.47$ \\
\hline Q4 & \multicolumn{2}{|c|}{$P$ for trend $=0.054$} & \multicolumn{2}{|c|}{$\begin{array}{l}1 \text { (reference) } \\
P \text { for trend }=0.622\end{array}$} \\
\hline \multicolumn{5}{|c|}{ Ca intake in cohort II } \\
\hline Q1 & 1.82 & $0.91,3.63$ & $1 \cdot 13$ & $0.47,2.73$ \\
\hline Q2 & $1 \cdot 60$ & $0.91,2.79$ & 1.69 & $0.83,3.43$ \\
\hline Q3 & 1.55 & $0 \cdot 89,2 \cdot 70$ & $2 \cdot 01$ & $1.03,3.94$ \\
\hline Q4 & $\begin{array}{l}1 \text { (reference) } \\
P \text { for trend }=0.0\end{array}$ & & \multicolumn{2}{|l|}{$P$ for trend $=0.278$} \\
\hline \multicolumn{5}{|c|}{ Energy-adjusted $¥ \mathrm{Ca}$ intake in cohort II } \\
\hline Q1 & 1.84 & $1 \cdot 11,3.07$ & 1.89 & $0 \cdot 87,4 \cdot 12$ \\
\hline Q2 & 1.36 & $0.81,2.28$ & 1.72 & $0.88,3.38$ \\
\hline Q3 & 1.51 & $0.91,2.52$ & 1.65 & $0.84,3.26$ \\
\hline Q4 & \multicolumn{2}{|c|}{$\begin{array}{l}1 \text { (reference) } \\
P \text { for trend }=0.018\end{array}$} & \multicolumn{2}{|c|}{$\begin{array}{l}1 \text { (reference) } \\
P \text { for trend }=0.174\end{array}$} \\
\hline
\end{tabular}

Q1, first quartile; Q2, second quartile; Q3, third quartile; Q4, fourth quartile.

*For details of subjects and procedures, see Subjects and methods.

†Adjusted for age, body weight, smoking, alcohol drinking, frequency of sport activity, area, vitamin D intake and total energy.

$¥$ Adjusted by the residual method. reported by Cummings et al. ${ }^{(27)}$, whose study targeted Caucasian women in the USA aged 65 years and over (mean $\mathrm{Ca}$ intake $714 \mathrm{mg} / \mathrm{d}$ ). Similarly, the Rotterdam Study ${ }^{(28)}$, targeting Dutch men and women aged 55 years and over (mean Ca intake $1131 \mathrm{mg} / \mathrm{d}$ ), found no such association either. In addition, the European Prospective Osteoporosis Study reported no association between frequency of milk consumption and morphometric vertebral fractures in men and women aged 50-79 years (mean Ca intake $1136 \mathrm{mg} / \mathrm{d}$ ) ${ }^{(29)}$. A lack of association between $\mathrm{Ca}$ intake and vertebral fracture in these three reports

Table 5. Meta-analysis* of relative risk (RR) of vertebral fractures occurring within 10 years for women and men according to quartiles of calcium intake in cohorts I and IIt

\begin{tabular}{|c|c|c|c|c|}
\hline & Unadjusted RR & $95 \% \mathrm{Cl}$ & Adjusted RR & $95 \% \mathrm{Cl}$ \\
\hline \multicolumn{5}{|c|}{ Ca intake in women } \\
\hline Q1 & 1.65 & $1 \cdot 12,2.42$ & $2 \cdot 13$ & $1.23,3.67$ \\
\hline Q2 & 1.60 & $1 \cdot 09,2 \cdot 35$ & $1 \cdot 82$ & $1 \cdot 17,2 \cdot 85$ \\
\hline Q3 & $1 \cdot 19$ & $0.79,1.80$ & $1 \cdot 35$ & $0.86,2.14$ \\
\hline Q4 & 1 (reference) & & 1 (reference) & \\
\hline & \multicolumn{2}{|l|}{$P$ for trend $=0.004$} & \multicolumn{2}{|c|}{$P$ for trend $=0.001$} \\
\hline \multicolumn{5}{|c|}{ Energy-adjusted $¥ \mathrm{Ca}$ intake in women } \\
\hline Q1 & 1.93 & $1 \cdot 32,2 \cdot 83$ & 1.92 & $1 \cdot 28,2 \cdot 88$ \\
\hline Q2 & $1 \cdot 35$ & $0.90,2.04$ & $1 \cdot 30$ & $0.86,1.98$ \\
\hline Q3 & 1.43 & $0 \cdot 95,2 \cdot 14$ & 1.50 & $0.99,2.26$ \\
\hline Q4 & 1 (reference) & & \multirow{2}{*}{\multicolumn{2}{|c|}{$\begin{array}{l}1 \text { (reference) } \\
P \text { for trend }=0.002\end{array}$}} \\
\hline & \multicolumn{2}{|l|}{$P$ for trend $=0.001$} & & \\
\hline \multicolumn{5}{|c|}{ Ca intake in men } \\
\hline Q1 & 1.07 & $0 \cdot 64,1.77$ & $1 \cdot 03$ & $0.53,2.01$ \\
\hline Q2 & $1 \cdot 16$ & $0.71,1.91$ & $1 \cdot 22$ & $0.71,2.09$ \\
\hline Q3 & 1.29 & $0 \cdot 79,2 \cdot 10$ & 1.46 & $0.88,2.44$ \\
\hline Q4 & 1 (reference) & & \multirow{2}{*}{\multicolumn{2}{|c|}{$\begin{array}{l}1 \text { (reference) } \\
P \text { for trend }=0.515\end{array}$}} \\
\hline & \multicolumn{2}{|l|}{$P$ for trend $=0.936$} & & \\
\hline \multicolumn{5}{|c|}{ Energy-adjusted $\ddagger \mathrm{Ca}$ intake in men } \\
\hline Q1 & 1.29 & $0 \cdot 78,2 \cdot 15$ & 1.46 & $0.82,2.61$ \\
\hline Q2 & $1 \cdot 17$ & $0 \cdot 68,2 \cdot 01$ & $1 \cdot 20$ & $0.68,2.09$ \\
\hline Q3 & 1.60 & $0.98,2.58$ & 1.68 & $1.02,2.74$ \\
\hline Q4 & \multirow{2}{*}{\multicolumn{2}{|c|}{$\begin{array}{l}1 \text { (reference) } \\
P \text { for trend }=0.646\end{array}$}} & \multirow{2}{*}{\multicolumn{2}{|c|}{$\begin{array}{l}1 \text { (reference) } \\
P \text { for trend }=0.450\end{array}$}} \\
\hline & & & & \\
\hline
\end{tabular}

Q1, first quartile; Q2, second quartile; Q3, third quartile; Q4, fourth quartile.

${ }^{*}$ Calculated from the weighted average of results from separate logistic regressions

fitted to the individual cohorts.

†For details of subjects and procedures, see Subjects and methods.

$\ddagger$ Adjusted by the residual method. 
may be partly due to the relatively high baseline $\mathrm{Ca}$ intake of their target populations, as compared with the population in the JPHC Study. A meta-analysis of randomized controlled trials examining the effect of $\mathrm{Ca}$ supplementation showed that RR of vertebral fracture was 0.77 (95\% CI 0.54, 1.09), suggesting that $\mathrm{Ca}$ supplementation was providing a statistically insignificant trend toward reduction in vertebral fractures ${ }^{(30)}$. Given the results of these previous studies, which studied mainly Caucasian populations with a relatively high $\mathrm{Ca}$ intake, $\mathrm{Ca}$ intake may not be a major predictor of incident vertebral fractures.

A positive result of the present study may be interpreted as lower $\mathrm{Ca}$ intake being associated with a higher incidence of vertebral fractures in peri- and post-menopausal populations with an already low $\mathrm{Ca}$ intake. There has been a similar large cohort study on hip fractures in Japan ${ }^{(31)}$, which reported that those who drank milk less than once per week had 1.7 times higher risk of hip fractures than those who drank milk five or more times per week. These results, much like the present study results, suggest that low $\mathrm{Ca}$ intake may adversely affect the incidence of fractures among the Japanese, especially in women.

Some epidemiological studies on fractures among Chinese populations have been conducted. Lau et al. ${ }^{(32)}$ conducted a case-control study in the late 1980s, which showed an inverse association between $\mathrm{Ca}$ intake and hip fractures. Chan et al. ${ }^{(33)}$ reported an OR of 2.1 (95\% CI 1.1, 3.9) for vertebral fracture, comparing the lowest quartile relative to the highest quartile. These results are consistent with the findings of the present study.

The incidence of vertebral fractures in this study was low. This may be due to the fact that the present study relied on self-reported vertebral fractures, which does not capture underlying vertebral fractures that can only be diagnosed by radiography. Fujiwara et al. ${ }^{(34)}$ reported that the annual incidence of radiographically diagnosed vertebral fractures in Japanese women in their 50s was five per 1000 personyears. In contrast, the current study found a 10-year cumulative incidence of $0.55 \%$ for self-reported vertebral fractures in women in the same age range, a value equivalent to about one-tenth that of the Fujiwara study. Radiographically diagnosed vertebral fractures include both symptomatic and asymptomatic fractures. It has been reported that more than $80 \%$ of elderly Japanese women with radiographically diagnosed vertebral fractures are asymptomatic ${ }^{(35)}$. On the other hand, self-reported vertebral fractures are more likely to be symptomatic. In the above-mentioned Muramatsu cohort study, all seven self-reported vertebral fractures were symptomatic. This has an important implication, suggesting that increased $\mathrm{Ca}$ intake may prevent symptomatic vertebral fractures in women whose habitual intake of $\mathrm{Ca}$ is low.

The 10-year incidence of self-reported vertebral fractures in the present study was higher in women than men with a female:male ratio of $1.4(0.55 \%: 0.39 \%)$. A study in Japanese people on the incidence of vertebral fractures, using radiographic methods that can detect asymptomatic fractures, showed that the age-adjusted incidence is twice as high in women as in men ${ }^{(34)}$. Although there is a real sex difference in the incidence of vertebral fractures, the magnitude of the difference varies according to the method used to identify fractures. It has been suggested that asymptomatic vertebral fractures may be more prevalent in women than men.
The population-attributable fraction of a vertebral fracture in women for the first quartile relative to the fourth was as high as $27 \%$. This has important implications for vertebral fracture prevention, given the high prevalence of low $\mathrm{Ca}$ intake among Japanese women with high prevalence of underlying vertebral fractures.

The FFQ used in cohort II apparently underestimated nutrient intakes. The major reason for this may be that the portion sizes in the FFQ were too small ${ }^{(12)}$. Validation of this FFQ was conducted by comparing the FFQ data with the $7 \mathrm{~d}$ diet record of a subset of the sample ${ }^{(16)}$ in a standardized manner ${ }^{(17)}$. Thus, although the FFQ may give low absolute values, it is still useful in terms of the ranking of subjects.

The present study has several strengths. The JPHC Study is the largest nationwide population-based cohort study in Japan. Furthermore, a large sample size enabled us to detect vertebral fractures in middle-aged and early elderly women and men. Therefore, the results of this study can be generalized to middle-aged and early elderly people in Japan whose Ca intake is generally low. Nevertheless, the current study has some limitations. First, we used a self-report method for identifying fracture cases. Although the self-reported vertebral fractures were considered to be highly specific, they may not have been very highly sensitive. Consequently, the present results may have been biased by misclassification in identifying vertebral fractures. If the misclassification was undifferentiated, the association between $\mathrm{Ca}$ intake and the occurrence of vertebral fractures would be expected to attenuate towards the null. This was the major limitation of the current study. Second, like other FFQ-based studies, the accuracy (correlation with a $7 \mathrm{~d}$ record method) of estimating $\mathrm{Ca}$ intake by FFQ in this study was not high and, therefore, its potential measurement bias may have attenuated the association between $\mathrm{Ca}$ intake and the occurrence of vertebral fractures. Furthermore, there may have been an unknown third factor that yielded a spurious association. This possible third factor may have been physical activity level, which we did not evaluate sufficiently, and which should be further examined in future studies. Third, the present results may have been influenced by selection bias because approximately $24 \%$ of the subjects did not return the follow-up questionnaire. On average, the difference in $\mathrm{Ca}$ intake between subjects who remained in the study and subjects who did not return the follow-up questionnaire was slight $(6 \mathrm{mg} / \mathrm{d}$ lower for the dropouts). Therefore, the impact of selection bias in terms of $\mathrm{Ca}$ intake may be minimal. Fourth, we could not evaluate $\mathrm{Ca}$ supplementation. However, the proportion of subjects who use $\mathrm{Ca}$ supplements in the present population is only $0.4 \%$ (unpublished results) and thus the effects of Ca supplementation in the present study were considered to be negligible. Finally, the present study used an observational design, which cannot eliminate all confounders. We considered many demographic and lifestyle factors as possible confounding variables; however, many other factors, including genetic factors, were not taken into account. Ideally, intervention studies are needed to remedy this problem.

The present study first demonstrated that there is an inverse association between $\mathrm{Ca}$ intake and clinical vertebral fractures. Our findings indicate that Japanese women, aged 40-69 years, with the lowest (approximately $<350 \mathrm{mg} / \mathrm{d}$ ) quartile of $\mathrm{Ca}$ intake had a two-fold higher risk than those with high $\mathrm{Ca}$ 
intake (approximately $\geq 700 \mathrm{mg} / \mathrm{d}$ ). This suggests that increasing the Ca intake could prevent vertebral fractures in peri- and post-menopausal female populations with low $\mathrm{Ca}$ intake. It then follows that $\mathrm{Ca}$ supplementation could be considered to increase $\mathrm{Ca}$ intake. Prior evidence has shown that $\mathrm{Ca}$ supplementation of $1000-1200 \mathrm{mg}$ (plus $20 \mu \mathrm{g}$ vitamin D) daily reduces fracture incidence ${ }^{(36)}$. However, such a high amount of $\mathrm{Ca}$ supplementation may prove to be too high for a lowCa-intake population, resulting in an increase of side effects. Whether the increase of $\mathrm{Ca}$ intake with a lower dose of $\mathrm{Ca}$ could prevent vertebral fracture warrants future studies.

\section{Acknowledgements}

We wish to thank all staff members in each study area and in the central offices for their cooperation and technical assistance. This study was supported by Grants-in-Aid for Cancer Research (16shi-2), for the 3rd Term Comprehensive 10-Year-Strategy for Cancer Control (H18-sanjigan-ippan-001) and for Research on Risk of Chemical Substances (H17-kagaku-ippan-014) from the Ministry of Health, Labour and Welfare of Japan and Grantsin-Aid for Scientific Research on Priority Areas from the Ministry of Education, Culture, Sports, Science and Technology (17015049). The authors had no conflict of interest.

\section{References}

1. Marcus R \& Majumder S (2001) The nature of osteoporosis. In Osteoporosis, 2nd ed., pp. 3-17 [R Marcus, D Feldman and J Kelsey, editors]. San Diego, CA: Academic Press.

2. Greendale GA \& Barrett-Connor E (2001) Outcomes of osteoporotic fractures. In Osteoporosis, 2nd ed., pp. 819-829 [R Marcus, D Feldman and J Kelsey, editors]. San Diego, CA: Academic Press.

3. Hashimoto T, Sakata K \& Yoshimura N (1997) Epidemiology of osteoporosis in Japan. Osteoporos Int 7, Suppl. 3, S99-S102.

4. Ross PD, Fujiwara S, Huang C, Davis JW, Epstein RS, Wasnich RD, Kodama K \& Melton LJ III (1995) Vertebral fracture prevalence in women in Hiroshima compared to Caucasians or Japanese in the US. Int J Epidemiol 24, 1171-1177.

5. Standing Committee on the Scientific Evaluation of Dietary Reference Intakes, Food and Nutrition Board, Institute of Medicine (1997) Dietary Reference Intakes for Calcium, Phosphorus, Magnesium, Vitamin D, and Fluoride. Washington, DC: National Academy Press.

6. Society for Information on Health and Nutrition (2006) The National Health and Nutrition Survey in Japan, 2003. Tokyo: Daiichi Shuppan (in Japanese).

7. Ministry of Health, Labour, and Welfare, Japan (2004) Dietary Reference Intakes for Japanese, 2005. Tokyo: Ministry of Health, Labour, and Welfare, Japan (in Japanese).

8. Nakamura K, Hori Y, Nashimoto M, Okuda Y, Miyazaki H, Kasai Y \& Yamamoto M (2004) Dietary calcium, sodium, phosphorus, and protein, and bone metabolism in elderly Japanese women: a pilot study using the duplicate portion sampling method. Nutrition 20, 340-345.

9. Yamaguchi J, Truman G \& Cameron ID (2000) Lifestyle factors affecting bone ultrasonometry of the calcaneus in Japanese women. Calcif Tissue Int 66, 43-46.

10. Fujita T \& Fukase M (1992) Comparison of osteoporosis and calcium intake between Japan and the United States. Proc Soc Exp Biol Med 200, 149-152.

11. Iga T, Dohmae Y, Endo N \& Takahashi HE (1999) Increase in the incidence of cervical and trochanteric fractures of the proximal femur in Niigata Prefecture, Japan. $J$ Bone Miner Metab 17, 224-231.

12. Tsugane S \& Sobue T (2001) Baseline survey of JPHC Study: design and participation rate. Japan Public Health Center-based Prospective Study on Cancer and Cardiovascular Diseases. J Epidemiol 11, Suppl. 6, S24-S29.

13. Kobayashi M, Tsubono Y, Otani T, Hanaoka T, Sobue T \& Tsugane S, JPHC Study Group (2004) Fish, long-chain $n$-3 polyunsaturated fatty acids, and risk of colorectal cancer in middle-aged Japanese: The JPHC Study. Nutr Cancer 49, 32-40.

14. Watanabe S, Tsugane S, Sobue T, Konishi M \& Baba S (2001) Study design and organization of the JPHC Study. J Epidemiol 11, S3-S7.

15. Tsubono Y, Kobayashi M, Sasaki S \& Tsugane S, JPHC (2003) Validity and reproducibility of a self-administered food frequency questionnaire used in the baseline survey of the JPHC Study Cohort I. J Epidemiol 13, Suppl. 1, S125-S133.

16. Ishihara J, Sobue T, Yamamoto S, Yoshimi I, Sasaki S, Kobayashi M, Takahashi T, litoi Y, Akabane M \& Tsugane S, JPHC (2003) Validity and reproducibility of a self-administered food frequency questionnaire in the JPHC Study Cohort II: study design, participant profile and results in comparison with Cohort I. J Epidemiol 13, Suppl. 1, S134-S147.

17. Tsubono $\mathrm{Y}$, Sasaki S, Kobayashi M, Akabane M \& Tsugane S (2001) Food composition and empirical weight methods in predicting nutrient intakes from food frequency questionnaire. Ann Epidemiol 11, 213-218.

18. Science and Technology Agency (2002) Standard Tables of Food Composition in Japan, 5th ed. Tokyo: Printing Bureau, Ministry of Finance (in Japanese).

19. Willett W (1990) Nutritional Epidemiology. New York: Oxford University Press.

20. Rothman KJ \& Greenland S (editors) (1998) Modern Epidemiology. Philadelphia, PA: Lippincott-Raven Publishers.

21. Rockhill B, Newman B \& Weinberg C (1998) Use and misuse of population attributable fractions. Am J Public Health $\mathbf{8 8}$ $15-19$.

22. Ministry of Health and Welfare, Japan (1993) The National Health and Nutrition Survey in Japan, 1991. Tokyo: Ministry of Health and Welfare, Japan (in Japanese).

23. Chen Z, Kooperberg C, Pettinger MB, Bassford T, Cauley JA, LaCroix AZ, Lewis CE, Kipersztok S, Borne C \& Jackson RD (2004) Validity of self-report for fractures among a multiethnic cohort of postmenopausal women: results from the Women's Health Initiative observational study and clinical trials. Menopause 11, 264-274.

24. Nakamura K, Saito T, Nishiwaki T, Ueno K, Nashimoto M, Okuda Y, Tsuchiya Y, Oshiki R, Muto K \& Yamamoto M (2006) Correlations between bone mineral density and demographic, lifestyle, and biochemical parameters in community dwelling Japanese women 69 years of age and over. Osteoporos Int 17, 1202-1207.

25. Orimo H, Sugioka Y, Fukunaga M, et al. (1998) Diagnostic criteria of primary osteoporosis. J Bone Miner Metab 16, 139-150.

26. Nakamura T \& Fujiwara S (1999) Vertebral and hip fractures in Japan. Bull World Health Organ 77, 430-431.

27. Cumming RG, Cummings SR, Nevitt MC, Scott J, Ensrud KE, Vogt TM \& Fox K (1997) Calcium intake and fracture risk: results from the study of osteoporotic fractures. Am J Epidemiol 145, 926-934.

28. van der Klift M, de Laet CE, McCloskey EV, Johnell O, Kanis JA, Hofman A \& Pols HA (2004) Risk factors for incident vertebral fractures in men and women: the Rotterdam Study. $J$ Bone Miner Res 19, 1172-1180.

29. Roy DK, O'Neill TW, Finn JD, et al., European Prospective Osteoporosis Study (EPOS) (2003) Determinants of incident vertebral 
fracture in men and women: results from the European Prospective Osteoporosis Study (EPOS). Osteoporos Int 14, 19-26.

30. Shea B, Wells G, Cranney A, et al. (2002) Meta-analyses of therapies for postmenopausal osteoporosis. VII. Meta-analysis of calcium supplementation for the prevention of postmenopausal osteoporosis. Endocr Rev 23, 552-559.

31. Fujiwara S, Kasagi F, Yamada M \& Kodama K (1997) Risk factors for hip fracture in a Japanese cohort. J Bone Miner Res 12, 998-1004.

32. Lau E, Donnan S, Barker DJ \& Cooper C (1988) Physical activity and calcium intake in fracture of the proximal femur in Hong Kong. BMJ 297, 1441-1443.
33. Chan HH, Lau EM, Woo J, Lin F, Sham A \& Leung PC (1996) Dietary calcium intake, physical activity and the risk of vertebral fracture in Chinese. Osteoporos Int 6, 228-232.

34. Fujiwara S, Kasagi F, Masunari N, Naito K, Suzuki G \& Fukunaga M (2003) Fracture prediction from bone mineral density in Japanese men and women. J Bone Miner Res 18, 1547-1553.

35. Kamide N, Sumide S, Watanabe T, Lmura T, Shibata Y \& Satoh $\mathrm{H}$ (2007) The relationship between a previous vertebral fracture and physical function in patients with osteoporosis. $J$ Jpn Phys Ther Assoc 34, 10-15, (in Japanese).

36. Dawson-Hughes B (1998) Vitamin D and calcium: recommended intake for bone health. Osteoporos Int 8, Suppl. 2, S30-S34. 